\title{
ILCEA
}

Revue de l'Institut des langues et cultures

d'Europe, Amérique, Afrique, Asie et Australie

$25 \mid 2016$

De la bibliothèque intérieure à la bibliothèque collective : livres et lectures en Espagne (XVI $\mathrm{I}^{\mathrm{e}} \mathrm{XX \textrm {I } ^ { \mathrm { e } }}$ siècles)

\section{Los libros y lecturas de un poeta áureo: Diego de Silva y Mendoza, conde de Salinas}

Livres et lecteurs d'un poète du Siècle d'or: Diego de Silva y Mendoza, comte de Salinas

The Books and Readings of a Golden-Age Poet: Diego de Silva y Mendoza, Count of Salinas

Trevor J. Dadson

URL: http://journals.openedition.org/ilcea/3758

DOI: 10.4000/ilcea.3758

ISSN: 2101-0609

Editor

UGA Éditions/Université Grenoble Alpes

Edición impresa

ISBN: 978-2-84310-322-3

ISSN: $1639-6073$

Referencia electrónica

Trevor J. Dadson, « Los libros y lecturas de un poeta áureo: Diego de Silva y Mendoza, conde de Salinas », ILCEA [En línea], 25 | 2016, Publicado el 31 enero 2016, consultado el 20 abril 2019. URL : http://journals.openedition.org/ilcea/3758; DOI : 10.4000/ilcea.3758

Este documento fue generado automáticamente el 20 abril 2019.

(C) ILCEA 


\section{Los libros y lecturas de un poeta áureo: Diego de Silva y Mendoza, conde de Salinas}

Livres et lecteurs d'un poète du Siècle d'or : Diego de Silva y Mendoza, comte de Salinas

The Books and Readings of a Golden-Age Poet: Diego de Silva y Mendoza, Count of Salinas

Trevor J. Dadson

Es un lugar común imaginar que el saber qué libros tenía cualquier escritor nos dará acceso a sus pensamientos, sus lecturas, sus fuentes y su mundo mental. Y en parte tendríamos razón. No puede haber duda de que entrar en ese mundo personal de lecturas abre muchas puertas al pensamiento y formación intelectual de cualquier poeta, novelista o dramaturgo. Pero al mismo tiempo no abre todas las puertas; algunas quedan firmemente cerradas. Para empezar, nunca sabremos si hemos encontrado todos los libros que un individuo poseía en su biblioteca particular, y tampoco sabremos si esos mismos libros representan todas sus lecturas. ¿Qué pasa con los libros prestados o los libros perdidos, o los libros leídos en, por ejemplo, otra casa? Y ¿qué decir de las lecturas recordadas de las aulas universitarias, que en realidad no lo son, pues son recuerdos normalmente mal aprendidos? Y, finalmente, ¿qué hacemos con las polianteas, florilegios y repertorios de sentencias que tanto escritor áureo minaba a la búsqueda de citas o frases memorables (López Poza, 1990)? No son libros que se suelen encontrar en las bibliotecas particulares, pero sabemos que todos los escritores las utilizaban como atajo para no tener que ir a la fuente original. Siempre que encontramos la frase tipo «Como Séneca dijo a otro propósito...», podemos estar casi seguros de que el autor está echando mano de alguna poliantea o algún recuerdo lejano (Dadson, 2002).

Puede sorprender que tengamos a nuestra disposición pocas bibliotecas de escritores áureos, y muy pocas de los escritores más destacados. Sabemos bastante, aunque no todo, de los libros que tenía Francisco de Quevedo, lo mismo que de Fernando de Rojas, Diego 
Hurtado de Mendoza, Fernando de Herrera, Alonso de Barros, Juan de Mal Lara, Luis Barahona de Soto, Rodrigo Caro, Antonio de Solís, pero nada de los que pertenecían a, por ejemplo, Garcilaso de la Vega, Miguel de Cervantes, Luis de Góngora, Lope de Vega, Pedro Calderón de la Barca ${ }^{1}$. Daniel Eisenberg, en sendos trabajos, ha intentado reconstruir la «biblioteca» de Cervantes a base de todos los autores y libros que citaba, pero reconociendo que el resultado no es la biblioteca que Cervantes pudo haber tenido, si es que la tuvo (Eisenberg, 1986 y 1987).

Otro problema que presentan muchas bibliotecas es que la lista de libros procede de un inventario post-mortem, y los problemas de los inventarios post-mortem son bien conocidos: 1) el inventario es en sí un acto económico (en palabras de Weruaga Prieto, 1993: 31), es decir, los libros listados en tal inventario están allí porque se van a vender, probablemente en almoneda pública, aunque es posible que algunos - ¿la minoría, la mayoría? - se hayan retirado o guardado aparte porque los quería algún miembro de la familia; 2) un inventario post-mortem solamente puede listar los libros en posesión del propietario en el momento de su muerte; como dijo Chevalier, «Es de temer que los inventarios después de la muerte no nos revelen las aficiones de un hombre, sino las lecturas de un anciano» (1976: 44), aunque, por supuesto, las lecturas de un anciano bien pueden haber sido las lecturas de un joven, y en todo caso el hecho de que alguien compró alguna vez determinados libros revela algo de sus intereses de lectura en alguna etapa de su vida.

Por razones obvias, un inventario o varios inventarios hechos durante la vida del lector son los más útiles, ya que nos revelan las lecturas del individuo en distintos momentos de su vida, pero ésos son los que menos se encuentran, y cuando sí se hallan, presentan a veces otros problemas de interpretación. Cuando estudié la biblioteca del escritor de Tudela Juan Francisco de Tornamira y Soto, tenía la suerte de poder examinar tres inventarios: el primero era unos pocos libros sueltos que mandó desde Zaragoza a su nueva casa en Tudela entre 1620 y 1622; el segundo era una lista de 23 títulos, su memoria de los libros que tenía en Tudela en mayo de 1623; y el tercero era la relación de libros que poseía en octubre de 1630, un total de 64 entradas (Dadson, 1998: 187-204). Curiosamente (o no), estas tres listas no coinciden en todo. Diez títulos de la lista de 1623 pasaron a la de 1630, pero 13 han desaparecido, entre ellos el Sumario de la historia del rey don Jaime de Aragón del propio Tornamira.

Algo parecido pasa con los distintos inventarios que he podido reunir del poeta y político Diego de Silva y Mendoza²: son cuatro en total, que van desde 1603 hasta 1630, año de la muerte del poeta, y luego 1642, y que representan tres distintos lugares de posesión: Valladolid (1603), Villarrubia de los Ojos (c. 1617), y el Palacio de Buenavista en Madrid (1630 y 1642). En orden de confección son: Inventario A Palacio de los condes de Salinas y Ribadeo, Valladolid (1603); Inventario B Palacio de los condes de Salinas y Ribadeo, Villarrubia de los Ojos (c. 1617); Inventario C Palacio de Buenavista, Madrid (1630); Inventario D Palacio de Buenavista, Madrid (1642)3. El número de títulos listados es el que sigue:

- Inventario A: 7;

- Inventario B: 138;

- Inventario C: 11 , más 54 «cuerpos de libros diferentes en latín e italiano y en romance de diferentes historias» (Archivo Histórico Provincial, Zaragoza [AHPZ], Casa Ducal de Híjar, $4^{\mathrm{a}}$ $-144)$; 
- Inventario D: 104 (Archivo Histórico de la Nobleza, Toledo [AHNT], Osuna, C. 3.910, D. 148, fols. $14 r-18$ r y $35 r-36 r)$.

Entre los cuatro inventarios hay muy poca repetición: los Soliloquios de San Agustín (en una edición rota y sin encuadernar) que Salinas tenía en Valladolid en 1603 es el número 78 del inventario $\mathrm{B}$, mientras que las Obras de Ludovico Blosio que estaban en el Inventario B, número 68, aparecen luego en el Inventario C. Siete de los títulos del nuevo inventario encontrado, el D, se encuentran en inventarios anteriores. Por tanto, de las 262 entradas que tenemos en total, hay nueve repeticiones, lo que nos deja con una biblioteca de unas 253 entradas, número más que respetable para la época, y una de las más grandes de su familia: su hermano mayor Rodrigo solamente reunió una colección de treinta y seis títulos (aunque en aras de la verdad, murió a la temprana edad de 33 años); mientras que la de su sobrino Ruy Gómez de Silva, III duque de Pastrana, llegó a los 94 (Dadson, 2011a).

Cuando publiqué por primera vez un estudio de los libros y lecturas de Diego de Silva y Mendoza (Dadson, 1994-1995), luego re-publicado con adiciones y correcciones en Dadson (1998), quedaba el misterio de esos 54 «cuerpos de libros diferentes en latín e italiano y en romance de diferentes historias» listados en un inventario hecho de los bienes del conde después de su muerte el 15 de junio de 1630. El inventario lo organizó su nuera, Isabel Margarita Fernández de Híjar, duquesa de Híjar, y da la impresión de que quien hiciera el inventario de los libros se hartó y no quiso listar más títulos. En todo caso, ese inventario no se hizo para vender los libros, sino para que quedara el recuento de ellos para el nuevo conde y duque, Rodrigo Sarmiento de Silva y Villandrando. Los libros de su padre Diego no iban a salir de la familia, y esto queda muy claro en el epígrafe que se pone al principio del nuevo inventario:

Inventario de los libros latinos, italianos, portugueses, castellanos, franceses y de las ciudades del orbe, estampados unos de colores y otros de tinta, que se hallaron en la guardarropa y en diferentes partes, que eran del marqués mi señor de Alenquer y ahora son del duque mi señor de Híjar, su hijo, y lo mandó hacer su excelencia a 25 de septiembre del año 1642 (AHNT, Osuna, C. 3.910, D. 148, fol. 14r).

Nada más encontrar este nuevo inventario, me hice la pregunta: ¿estarían aquí los 54 libros mencionados antes, pero sin diferenciar? Es imposible saberlo, pero el epígrafe dice claramente que son «latinos, italianos, portugueses, castellanos, franceses», y esto recuerda bastante la entrada anterior: «libros diferentes en latín e italiano y en romance de diferentes historias». Por tanto, lo más probable es que hayamos encontrado esos libros que faltaban en el inventario de 1630. Otro aspecto del epígrafe que hay que destacar es la información muy puntual de que estos libros se hallaban «en la guardarropa y en diferentes partes»; es decir, estaban esparcidos por todo el palacio, y no, al parecer, en un cuarto o aposento dedicado a librería, aunque, por otras indicaciones, parece que la guardarropa servía como aposento particular o recámara de Salinas: estaba ricamente decorada con tapicerías (de la historia de Tobías), reposteros «de paño azul con las armas de la Casa», y alfombras de lana y seda de la China (AHNT, Osuna, C. 3.910, D. 199, fols. 3r, 5r-v). Por otro inventario, sabemos que los libros se guardaban en cajas y no en estantes: «Una caxa con ochenta y vn cuerpos de libros grandes y pequeños» ( AHNT, Osuna, C. 3.910, D. 199, fol. 43r).

El nuevo inventario está dividido en distintas secciones, tituladas así: libros latinos (47 entradas); libros italianos y franceses (17 entradas); un grupo de libros «que entraron en la Galería» el 7 de octubre de 1642 (11 entradas); libros portugueses (4 entradas); y libros de romance, es decir en castellano (25 entradas). Cuando solamente disponíamos del Inventario B (de Villarrubia, c. 1617), escribí: «En cuanto a su formación intelectual 
podemos decir, basándonos en la evidencia de este inventario, que Salinas sabía leer, además del castellano, latín, portugués, italiano (seguramente), francés (probablemente)» (Dadson, 1998: 211). Ahora podremos quitar los dos adverbios en paréntesis: leía también el italiano y el francés, y, tal vez (como veremos), el alemán. A los pocos libros en italiano de los inventarios anteriores, ahora podemos añadir: las cartas de Ovidio comentadas por Remigio (n. $\left.{ }^{\circ} 49\right)$ más los Metamorfóseos del mismo (n. $\left.{ }^{\circ} 50\right)$, un poema épico sobre el Nuevo Mundo en cuatro cantos de fray Tommaso Stigiliani (n. $\left.{ }^{\circ} 51\right)$, tres obras de Petrarca (n. ${ }^{\circ}$ 53, 55 y 62), un Dante impreso en Lyon (n. ${ }^{\circ} 57$ ), La Gerusalemme liberata de Torcuato Tasso (n. $\left.{ }^{\circ} 59\right)$, las obras de un tal Dámaso Trianber, sin identificar (n. $\left.{ }^{\circ} 60\right)$, y los anales de Tácito (n. ${ }^{\circ}$ 61). Además de los libros en italiano listados en su sección, Salinas tenía otros en la sección titulada «Libros que entraron en la Galería», la mayoría de temática militar: tres libros de fortificación (n. ${ }^{\circ}$ 67-69), la Disciplina militare de Aurelio Cicuta (n. $\left.{ }^{\circ} 74\right)$, una obra de arquitectura de Vigniola (n. $\left.{ }^{\circ} 66\right)$, y un libro sobre la peste en Cerdeña por Quinto Tiberio Angelerio (n. $\left.{ }^{\circ} 75\right)$. La variedad de temas sugiere que Salinas tenía pocos problemas leyendo el italiano, aunque del Inventario B vemos que tenía dos diccionarios de italianoespañol (n. $\left.{ }^{\circ} 133\right)$, más otro «de diferentes lenguas» sin especificar (n. $\left.{ }^{\circ} 135\right)$. En este nuevo inventario tenía «un vocabulario de tres lenguas por el maestro Felipe Cortona» $\left(\mathrm{n} .{ }^{\circ} 18\right)$, es decir, Filippo Venuti da Cortona. Era autor de numerosos diccionarios de italiano y latín y de italiano y francés, pero no hemos encontrado uno de tres lenguas, aunque lo más probable es que fuera un diccionario de latín, italiano y francés, como los que imprimía Robert Estienne.

En francés tenía las obras de Tácito (n. $\left.{ }^{\circ} 48\right)$, las memorias de Martín du Bellay (n. $\left.{ }^{\circ} 52\right)$, la vida de los hombres ilustres de Plutarco (n. $\left.{ }^{\circ} 54\right)$, El secretario cortesano de Jean Puget de la Serre (n. $\left.{ }^{\circ} 56\right)$, y las cosas memorables y singulares de Pierre Belon (n. $\left.{ }^{\circ} 58\right)$. Para ayudarle en sus lecturas de Tácito y Plutarco en francés, tenía el Dictionarium Latinogallicum de Robert Estienne el Mayor (Inventario B, n. ${ }^{\circ} 42$ ), además de versiones en latín, lengua que leía con facilidad ${ }^{4}$.

Una nueva lengua que aparece en este inventario es el alemán. Salinas poseía bastantes libros impresos en Alemania (en ciudades como Colonia, Fráncfort, y Hamburgo) pero «Las relaciones de Theodoro Merves en alemán en tres tomos» $\left(n .^{\circ} 63\right)$ es el único texto escrito en esa lengua: Theodori Meurers relationis historicae continuatio, oder warhafftige Beschreibung aller fürnemen und gedenckwürdigen Historien, Impressum Franckfurt: M. Latomus, 1600-1615. No obstante su presencia en su biblioteca, creemos poco probable que tuviera los suficientes conocimientos del alemán para poder leerlo.

En lengua portuguesa solamente encontramos 4 títulos aquí (los números 76-79), de los que solamente he podido identificar uno: Manuel Mendes de Castro, Repertorio das ordenações do Reyno de Portugal nouamente recopiladas (n. ${ }^{\circ}$ 78). En los anteriores inventarios encontramos 17 títulos en portugués en el Inventario B y dos en el Inventario C. Aunque Salinas era medio portugués por línea paterna (su padre era Ruy Gómez de Silva), sólo tenía 8 años y medio cuando su padre murió y es dudoso, por tanto, que aprendiera la lengua de él o en casa; por lo que sabemos, su madre no lo hablaba. Pero sus conocimientos de la lengua eran tales que llegó a escribir en portugués sin problemas y con mucha naturalidad. La cantidad de cartas suyas escritas en portugués y de su puño y letra, provenientes de los años que estuvo en Lisboa como Virrey y Capitán General, son una mina de información sobre sus habilidades en el portugués. Escribía directamente en portugués - no copiaba lo que otros, como su secretario de lengua portuguesa, Luis Abreu de Freitas, habían escrito o preparado para él- y solía volver a leer lo que había escrito 
corrigiendo las erratas que él mismo identificaba; normalmente eran erratas de confusión entre el portugués y el castellano o mala ortografía. Y el portugués que escribía no era simple; sabía manejar su sintaxis complicada con soltura, como alguien que lo leía, escribía y hablaba como un nativo. Todo esto sugiere que en algún momento de su vida tuvo un tutor de lengua portuguesa, tal vez en los primeros años del nuevo siglo cuando se barajaba su nombre como nuevo presidente del Consejo de Portugal en Madrid, puesto que llegó a ocupar a partir de 1605. Como Virrey de Portugal, tenía que escribir todas sus cartas dirigidas al Consejo de Portugal en portugués, a pesar de que todos los miembros de dicho Consejo eran capaces de leerlas en castellano, y no digamos del rey, Felipe III, que también las recibía en portugués si le llegaban vía ese Consejo, tal era el convenio establecido en las Cortes de Tomar de 1581. Por tanto, el mismo día podemos encontrar a Salinas escribiendo al rey tanto en castellano como en portugués, según el Consejo al que se dirigía. A veces se confundía, como el 23 de febrero de 1620 cuando escribió al secretario Martín de Aróztegui en una mezcla de ambas lenguas:

Jacomé de Morais me enviou o papel incluso que me pareceu que devia ver-se no Conselho para que por ele se veja o estado do apresto dos navios de Moçambique. V.m. le muestre y diga que la poca salud no me dejó fechar este despacho mais cedo [...] Danme agora una consulta da junta, otra do Conselho de Fazenda sobre Antonio Fernández de Elvas. Diga V.m. que es impossível que vá neste correo, que irá com outro 5 .

Da la impresión de que Salinas estaba en estos momentos escribiendo cartas en portugués y olvidó que su destinatario no era ni portugués ni secretario del Consejo de Estado de Portugal, a quienes siempre escribía en su lengua, como demandaba el acuerdo de Tomar.

En cuanto al resto de los libros del Inventario D (1642), hay de todos los temas: historia, derecho, religión, literatura, tanto obras clásicas como contemporáneas, que examinaremos en seguida, pero hay un grupo que destaca tal vez, y son los libros de escritores jesuitas. Tenía de Pedro de Ribadeneyra, Tratado de la religión y virtudes que deue tener el Principe Christiano para gobernar y conseruar sus estados..., libro escrito expresamente contra «lo que Nicolas Machiauelo y los Politicos deste tiempo enseñan» (n. $\left.{ }^{\circ} 82\right)$. Como el Príncipe de Maquiavelo estaba en el índice de libros prohibidos desde 1559, la única manera que un político español de principios del siglo xviI tenía para leerlo era vía obras como ésta de Ribadeneyra ${ }^{6}$. Las cartas que Salinas enviaba desde Lisboa en su papel de Virrey y Capitán General entre 1617 y 1622 demuestran hasta qué punto el político español había aprendido las lecciones del italiano. Curiosamente, el primer libro del Inventario D era un ejemplar del Index et Catalogus Librorum prohibiturum, mandato Illustriss. Ac Reverendiss. D. D. Gasparis a Quiroga. Cardinalis Archiepiscopi Toletani... (Madrid: Alonso Gómez, 1583)7. Como es natural, tenía otras obras de filosofía política, como Politicorum siue ciuilis dotrinae libri sex de Justo Lipsio (n. $\left.{ }^{\circ} 8\right)$, además de la traducción al castellano de Bernardino de Mendoza: Los seis libros de las políticas o doctrina civil (n. $\left.{ }^{\circ} 101\right)$. Es notable el número de libros que Salinas tenía al mismo tiempo en su versión original y traducidos. Aparte de otros motivos, era una muy buena manera de aprender a leer en una lengua extranjera.

Como Presidente del Consejo de Portugal, Salinas tenía bajo su responsabilidad todo lo concerniente a Oriente Lejano - la China y el Japón- y las posesiones portuguesas orientales y su comercio de especias. No extraña por tanto encontrar en anteriores inventarios suyos las relaciones anuales que mandaban los padres jesuitas desde Oriente (Inventario B, n. ${ }^{\circ \mathrm{1}}$ 107-109), y en éste la célebre obra de Mateo Ricci, De Christiana expeditione apud Sinas suscepta ab societate Iesu... libri $V$ (Inventario D, n. ${ }^{\circ}$ ). Otros libros de 
autores jesuitas eran: Jan David, Amputandum putabam radix stirps et germen errorum (contra los herejes y sus heresías; $n .^{\circ} 17$ ); un poema «en alabanza de su majestad del rey Felipe Tercero compuesto por un padre de la Compañía», tal vez las Lágrimas de Zaragoza en la muerte de Felipe II de Aragón, del padre Paulo de Rojas de la Compañía de Jesús (n. $\left.{ }^{\circ} 19\right)$; un «Aristóteles comentado por un padre de la Compañía de Jesús», probablemente de un jesuita de Coimbra (n. $\left.{ }^{\circ} 38\right)$; y la Esfera de Juan de Sacro Bosco comentado por Cristóbal Clavio, otro jesuita (n. $\left.{ }^{\circ} 42\right)$. Este interés en obras jesuitas se puede explicar quizá por la educación que Salinas recibió de joven. Parece probable que junto con su hermano mayor Rodrigo Diego fuese educado primero en la corte de Madrid, cuando sus padres vivían allí, asistiendo a uno de los colegios recién fundados por los jesuitas. Juan de la Cerda dedicó su Commentaria in omnia opera Publii Virgilii Maronis, de 1608, a Diego de Silva y Mendoza con estas palabras: «Tu una cum nobilissimis Fratribus tuis has SOCIETATIS IESV Scholas, illas cum primum aperuimus, incredibili studio frequentastis» ${ }^{8}$. Prosiguió el prologuista diciendo que esto fue por orden de Ruy Gómez de Silva, príncipe de Éboli, que si es verdad, da un terminus ad quem de 1573 para que aconteciera. Unos años más tarde, cuando los dos jóvenes duques vivían en Pastrana, entre 1573 y 1576, tuvieron un preceptor o ayo llamado Ruy Díaz de Mendoza (Dadson \& Reed, 2013: 290-291, doc. 139). También es posible que Díaz de Mendoza fuese su preceptor en Madrid y luego acompañase a la familia a Pastrana.

Otros temas interesantes que salen de este nuevo inventario son:

1. Libros contra herejes y herejías, como: el ya mencionado Jan David, Amputandum putabam radix stirps et germen errorum ( $\left.\mathrm{n}^{\circ} 17\right)$; Joannes Hessels, De officio pii, et christianae pacis vere amantis viri, exvrgente, avt vigente haeresi de 1566 (n. $\left.{ }^{\circ} 20\right)$; una obra de Conradus Brunus, autor de numerosos libros contra la sedición, los herejes, etc.; un libro titulado De Fide Haereticis Servanda ex decreto concilii Constantiensis dissertatio, in qua, quae de Husso historia est, de Daniel Plancius y Heribert Rosweyde, y dedicado a Jacobo Daza [Jacques Dassa], uno de los dos Burgomaestres de Amberes (n. $\left.{ }^{\circ} 22\right)$. Suponemos que Salinas cultivaba ese interés por sus contactos diarios con holandeses e ingleses en Lisboa, aunque muchas de sus cartas dejan entrever, más que hostilidad, una profunda admiración (y cierta envidia) de lo que habían conseguido esos dos pequeños países sin la población ni los recursos de España y sus dos imperios, pero con un enfoque decidido sobre el comercio, verdadera riqueza de las naciones en opinión de Salinas.

2. Asuntos específicos de Portugal y su imperio en el Oriente, como las relaciones con los holandeses: la Concordiae Belgicae Panegyricus Parnassicus de Jodocus de Weerdt (n. $\left.{ }^{\circ} 32\right)$, que celebra la Tregua de los Doce Años entre España y Holanda firmada el 9 de abril de 1609 en Amberes. Como Presidente del Consejo de Portugal Salinas había sido consultado sobre los términos del tratado y había contribuido con algunas advertencias muy acertadas sobre el probable comportamiento futuro de los rebeldes holandeses (Dadson, 2015: 202-206, doc. 201). También tenía un libro muy curioso titulado «Alegación en favor de la compañía de la India oriental [y] comercios ultramarinos por Duarte Gómez Solís» (n. ${ }^{\circ}$ 92), dedicada al conde-duque de Olivares en 1628.

3. Muchas historias de Oriente, África, la India, la China, las Américas, y una obra sobre las principales ciudades del mundo, de Georg Braun y Franz Hohenberg (n. ${ }^{\circ} 46$ ), con sus estampas, que se encontraba en el Inventario C (.$\left.^{\circ}{ }^{\circ} 146\right)$, aunque allí sólo se listaban dos tomos mientras que aquí son siete.

4. Libros técnicos, como: los Elementos de Euclides (n. ${ }^{\circ} 33$ ); las Fundamenta arithmetica et geométrica de Ludolph van Ceulen (n. $\left.{ }^{\circ} 40\right)$; la Trigonometriae de Bartolomaei Pitisci (n. $\left.{ }^{\circ} 41\right)$; el ya mencionado comentario sobre la esfera de Juan de Sacro Bosco (n. $\left.{ }^{\circ} 42\right)$, más otro libro en folio sobre la esfera sin identificar, pero probablemente impreso en Ámsterdam (n. $\left.{ }^{\circ} 64\right)$; un 
libro de médicos, medicina y anatomía de Joannes Bravus Chamissus, profesor de Coimbra (n. $\left.{ }^{\circ} 47\right)^{9}$; uno de «las doce divisiones geométricas» de Michel Coignet (n. ${ }^{\circ} 72$ ), otro de cosmografía de Apiano (n. $\left.{ }^{\circ} 73\right)$, y el Libro de la gineta de España de Pedro Fernández de Andrada (n. $\left.{ }^{\circ} 71\right)$. Es posible que algunas de estas obras sirviesen para la educación de su hijo Rodrigo. Sabemos que tuvo maestros para las siguientes asignaturas: leer, escribir, danzar, la gramática, las matemáticas, la cosmografía, la esgrima, la gineta, la brida, mientras que exhibía, según él, «grandes habilidades» en saltar, trepar, tirar y cortar ${ }^{10}$.

5. Algunos compendios de frases y dichos, muy útiles para las citas, como: Setentiae ex thesauris Graecorum delectae, quarum autores circiter ducentos \& quinquaginta citat de Ioannis Stobaei (n. ${ }^{\circ}$ 25); los jeroglíficos de Giovanni Pierio Valeriano (n. $\left.{ }^{\circ} 13\right)$; Francisco Sánchez de las Brozas [el Brocense], De arte dicendi liber unus, de 1573, libro que contiene sus comentarios sobre pasajes de la Eneida de Virgilio, muy útil para un poeta como Salinas (n. $\left.{ }^{\circ} 26\right)$. A estos podríamos, quizá, añadir el siguiente título: Ambrosio Nunes, Enarrationum priores tres libros aphorismorum Hippocratis cum paraphrasi in commentaris Galeni..., Coimbra: Diogo Gomez Louveyro, 1603 (n. ${ }^{\circ}$ ).

6. Autores clásicos comentados, como: Aristóteles, Horacio, Virgilio, Ovidio, Tácito, Séneca, Suetonio, Petrarca, y Dante; de nuevo, una rica fuente de citas para un poeta.

7. Algunos libros de religión muy curiosos, como: «Un libro de la regla de los carmelitas descalzos mandado imprimir por el papa Gregorio decimotercio», de 1585 (n. ${ }^{\circ} 11$ ), que habría que considerar al lado del libro sin especificar de Teresa de Jesús que tenía en el Inventario B número 129. Teniendo en cuenta los problemas que su madre la princesa de Éboli tuvo con la fundadora de las Carmelitas Descalzas, es interesante ver que su hijo favorito Diego poseyese este libro en particular ${ }^{11}$.

8. Bastantes obras de derecho que habrían sido fundamentales para alguien que presidía el Consejo de Portugal y luego fue Virrey del país luso: la Practica Lusitana, aduocatis, iudicibus, « en que se tratan cosas convenientes al Reino de Portugal» (n. $\left.{ }^{\circ} 9\right)$ y el Repertorio das ordenações do Reyno de Portugal nouamente recopiladas (n. ${ }^{\circ} 78$ ), ambas de Manuel Mendes de Castro; las Antigüedades de Lisboa de Lucio André de Resende (n. $\left.{ }^{\circ} 15\right)$; las Remisiones Doctorum de Officiis Publicis Jurisdictione de Manuel Barbosa (n. $\left.{ }^{\circ} 16\right)$; y la Execucion de Politicas y Brevedad de Despachos de Luis Álvarez de Correa (n. ${ }^{\circ}$ 97), muy a propósito para quien tuvo que despachar a diario.

9. Finalmente, tres libros de temática y/o autoría más personal: el Memorial de cosas notables de su pariente el IV duque del Infantado ( $\left.n .^{\circ} 86\right)$, libro cuya ausencia en anteriores inventarios nos sorprendió, ya que forma parte del ideario Mendoza; la Agonia del transito de la muerte con los auisos y consuelos que acerca della son prouechosos de Alejo Venegas (.$\left.^{\circ} 81\right)$, obra que trata de la muerte ejemplar de don Diego Hurtado de Mendoza, I conde de Mélito, en 1536 y que fue dedicada a su viuda doña Ana de la Cerda, bisabuela materna de Diego de Silva y Mendoza; y las Ephemerides generales de Francisco Suárez de Argüelles (n. $\left.{ }^{\circ} 104\right)$, libro de tablas astronómicas dedicado en 1608 al mismo Salinas (y que posiblemente figuraba en el inventario de 1617 [Inventario $B, n .^{\circ} 127$ ]).

Tomando en consideración los cuatro inventarios que tenemos ahora de los libros poseídos por el conde de Salinas, podemos decir que la suya era una biblioteca profesional de trabajo, de libros comprados o adquiridos para fines específicos en relación con las distintas facetas y fases de su vida y carrera: libros de literatura y entretenimiento (para el poeta); libros de historia, derecho, filosofía política, arte militar (para el político); libros de asignaturas escolares (comprados por el padre para el hijo único); libros de religión (para ambos). Como fueron confeccionados en distintas etapas de su vida, vemos cómo sus gustos cambiaban o progresaban, según el cargo que ocupaba o el lugar donde vivía. Los lugares de impresión de bastantes de sus libros -Lyon, Amberes, Lovaina, Lisboa, Venecia, Colonia, Hamburgo, Basilea, Zúrich, París, Coimbra, Jena, Roma, Fráncfort, 
Parma, Bruselas - sugieren que compraba los libros mediante agentes o en las ferias internacionales como la de Medina del Campo, donde libreros venidos de los principales centros europeos de producción como Lyon, Venecia, Roma, París, Amberes vendían sus últimas ofertas. Parece también seguro que aprovechara su estancia de cinco años en Lisboa para hacerse con bastantes libros en portugués. Al mismo tiempo, tenía libros impresos por las principales imprentas de España localizadas en Madrid, Salamanca, Burgos, Valladolid, Zaragoza, Valencia, Sevilla, y Alcalá de Henares.

En resumen, es una biblioteca cosmopolita, de una temática muy variada, con libros antiguos al lado de los más contemporáneos. Las lecturas de Diego de Silva y Mendoza abren una ventana privilegiada a su mundo mental, a cómo pensaba y, a veces, a cómo se expresaba en sus escritos. Es indudable que su educación a manos de los jesuitas seguida de sus múltiples lecturas de los padres de la Compañía le inculcara una manera muy ordenada y lógica de expresar sus pensamientos. Tanto en sus memoriales políticos como en sus cartas políticas organizaba sus ideas así: primero exponía los puntos a discutir, empleando a menudo frases del tipo «todo se reduce a los siguientes puntos», luego contestaba cada punto, con frecuencia numerándolos, como en este ejemplo de un memorial de 1623: «Cíñese todo lo que puede convenir en cuatro puntos: el primero es ver si conviene efectuar el casamiento y con qué concesiones; el segundo, si conviene no efectuarle y la salida que se ha de dar respecto del estado en que está la plática; el tercero, si conviene dilatarle; y el cuarto, si conviene abreviar la resolución» (Dadson, 2015: 380, doc. 447). Muchas veces empezaba una nueva sección con la frase «presupuesto que» o con la expresión «como la experiencia nos ha mostrado». Buscaba siempre lo que iba a funcionar y tener los efectos deseados. Haciendo eco de una de las principales lecciones de los jesuitas desarrollada en los ejercicios espirituales de San Ignacio, decía que primero se tenía que identificar el fin y luego buscar los medios para conseguirlo: «Es este género de cosas de la cualidad de aquellas que los fines las han de dar principio y el tenerlos antevistos convenientísimo para que sean acertadas las resoluciones», o «Ver los fines que han de tener las cosas desde los principios es empezar por el acierto de ellas», del mismo memorial de 1623 (Dadson, 2015: 376 y 379). Todo lo contrario de lo que predicaba Maquiavelo: que los fines justificaban los medios.

Salinas fue un buen alumno de los jesuitas, lo mismo que fue un lector atento de Lipsio, Maquiavelo (en la versión seguramente de Ribadeneyra), y otros pensadores políticos como los iberos Antonio de Herrera (Razón de estado [Inventario B, n. ${ }^{\text {os }} 105-06$ ]) y Francisco Alvia de Castro (Verdadera razón de estado [Inventario B, n. ${ }^{\circ} 116$ ]). Sus cinco años pasados en Lisboa unieron la experiencia práctica a la teoría, y Salinas acabó siendo uno de los políticos mejor preparados y más inteligentes de la España del primer tercio del siglo XVII. Como hemos dicho recientemente:

Seguramente fue por esto por lo que el conde-duque de Olivares lo apartara tan rápida e injustamente, a su regreso a Madrid en el verano de 1622, de los centros y resortes del poder. Reconoció en seguida en el conde de Salinas a un rival demasiado poderoso e inteligente para tenerlo cerca del rey. Así desaprovechó, para mal de España, un verdadero talento político (Dadson, 2015: 33). 


\section{BIBLIOGRAFÍA}

ALCOCER y MARTíNez Mariano (1926), Catálogo razonado de obras impresas en Valladolid (1481-1800), Valladolid: Imprenta de la Casa Social Católica.

ANSELMO António Joaquim (1926), Bibliografia das obras impressas em Portugal no século XVI, Lisboa: Oficinas Gráficas da Biblioteca Nacional.

BEARDSLEy Theodore S. Jr. (1970), Hispano-Classical Translations Printed Between 1482 and 1699, Pittsburgh: Duquesne University Press.

BRITISH LIBRARY (1924), Short-title Catalogue of Books printed in France and of French Books printed in other countries from 1470 to 1600 now in the British Museum, London: British Museum.

BRITISH LIBRARY (1958), Short-title Catalogue of Books printed in Italy and of Italian Books printed in other countries from 1465 to 1600 now in the British Museum, London: British Museum.

BRITISH LIBRARY (1962), Short-title Catalogue of Books printed in the German Speaking Countries and German Books printed in other countries from 1455 to 1600 now in the British Museum, London: British Museum.

BRITISH LIBRARY (1965), Short-title Catalogue of Books printed in the Netherlands and Belgium and of Dutch and Flemish Books printed in other countries from 1470 to 1600 now in the British Museum, London: British Museum.

BRITISH LIBRARY (1989), Catalogue of Books printed in Spain and of Spanish Books printed elsewhere in Europe before 1601 now in the British Library, London: British Library.

BRITISH LIBRARY (1990), Catalogue of Seventeenth-Century Italian Books in the British Library, 3 vols, London: The British Library.

CATALINA GARCíA Juan (1899), Biblioteca de escritores de la provincia de Guadalajara y bibliografía de la misma hasta el siglo XIX, Madrid: Sucesores de Rivadeneyra.

CHEVALIER Maxime (1976), Lectura y lectores en la España del siglo XVI y XVII, Madrid: Turner.

DADSON Trevor J. (1994-1995), «La biblioteca del poeta y político Diego de Silva y Mendoza, conde de Salinas (1564-1630)», Journal of Hispanic Research, 3, 181-216.

DADSON Trevor J. (1998), Libros, lectores y lecturas. Estudios sobre bibliotecas particulares españolas del Siglo de Oro, Madrid: Arco/Libros.

DADSON Trevor J. (2002), «A Golden-Age Poet and his Sources: Gabriel Bocángel y Unzueta», Stephen Boyd \& Jo Richardson (eds), Spanish Poetry of the Golden Age. Papers of a Colloquium held at University College Cork (21-39), Manchester: Department of Spanish and Portuguese Studies.

DADSON Trevor J. (2011a), «De libros a bibliotecas: el caso de los duques de Pastrana en los siglos XVI y XVII», O. Noble Wood, J. Roe \& J. Lawrance (eds), Poder y saber. Bibliotecas y bibliofilia en la época del conde-duque de Olivares (413-437), Madrid: Centro de Estudios Europa Hispánica.

DADSON Trevor J. (2011b), Diego de Silva y Mendoza. Poeta y político en la corte de Felipe III, Granada: Ediciones de la Universidad de Granada. 
DADSON Trevor J. (2015), Diego de Silva y Mendoza, Conde de Salinas, Marqués de Alenquer. Cartas y Memoriales (1584-1630), Madrid: Centro de Estudios Europa Hispánica - Marcial Pons Historia. DADSON Trevor J. (2016), Conde de Salinas. Obra completa: la poesía desconocida, Madrid: Real Academia Española, Biblioteca Clásica.

DADSON Trevor J. \& REED Helen H. (2013), Epistolario e historia documental de Ana de Mendoza y de la Cerda, princesa de Éboli, Madrid: Iberoamericana - Vervuert.

DíEz BoRQue José María (2010), Literatura (novela, poesía teatro) en bibliotecas particulares del Siglo de Oro español (1600-1650), Madrid: Universidad de Navarra - Iberoamericana - Vervuert.

DíEz Borque José María (dir.) \& Bustos TÁUler Álvaro (ed.) (2012), Literatura, bibliotecas y derechos de autor en el Siglo de Oro (1600-1700), Madrid: Universidad de Navarra - Iberoamericana - Vervuert. EISENBERG Daniel (1986), «Did Cervantes Have a Library?», Hispanic Studies in Honor of Alan D. Deyermond. A North American Tribute (93-106), Madison (Wisconsin): Hispanic Seminary of Medieval Studies.

EISENBERG Daniel (1987), «La biblioteca de Cervantes», Studia in honorem prof. M. de Riquer (vol. 2, 271-328), 3 vols, Barcelona: Quaderns Crema.

ENTRAMBASAGUAS Joaquín de (1943), La biblioteca de Ramírez de Prado, 2 vols, Madrid: C.S.I.C.

EsCUdERo y PEROSSO Francisco (1894), Tipografía Hispalense. Anales bibliográficos de la ciudad de Sevilla desde el establecimiento de la imprenta hasta fines del siglo XVIII, Madrid: Sucesores de Ribadeneyra. GAILLARD Claude (1983), Le Portugal sous Philippe III d'Espagne. L'action de Diego de Silva y Mendoza, Grenoble: Université des Langues et Lettres de Grenoble.

GoLDSMITH Valentine Fernande (1969-1973), A Short Title Catalogue of French Books 1601-1700 in the Library of the British Museum, London: Dawsons of Pall Mall.

GolDSMITH Valentine Fernande (1974), A Short Title Catalogue of Spanish and Portuguese Books 16011700 in the Library of the British Museum, London: Dawsons of Pall Mall.

GonZALO SÁNCHEZ Molero José Luis (1998), La «Librería rica» de Felipe II. Estudio histórico y catalogación, San Lorenzo del Escorial: Estudios Superiores del Escorial.

HAEBLER Konrad (1903-1917), Bibliografía ibérica del siglo XV, 2 vols, La Haya: M. Nijhohh. JiMÉNEZ CATALÁN Manuel (1927), Ensayo de una tipografía zaragozana del siglo XVII, Zaragoza: Tipografía «La Académica».

KINDER A. Gordon (1976), «Juan Pérez de Pineda (Pierius): A Spanish Calvinist Minister of the Gospel in Sixteenth-Century Geneva», Bulletin of Hispanic Studies, 53, 283-300.

LASPÉRAS Jean-Michel (1980), «Chronique du livre espagnol: inventaires de bibliothèques et documents de librairie dans le monde hispanique aux $\mathrm{XV}^{\mathrm{e}}, \mathrm{XVI}^{\mathrm{e}}$ et $\mathrm{XVII}{ }^{\mathrm{e}}$ siècles», Revue française d'histoire du livre, 28, 535-557.

LÓPEZ PozA Sagrario (1990), «Florilegios, polyantheas, repertorios de sentencias y lugares comunes: Aproximación bibliográfica», Criticón, 49, 61-76.

MARTín ABAD Julián (1991), La imprenta en Alcalá de Henares (1502-1600), 3 vols, Madrid: Arco/Libros. Martín Velasco Margarita (2009), La colección de libros impresos del IV Duque de Uceda en la Biblioteca Nacional de España. Estudio y Catálogo, Madrid: Calambur. 
MORENO GARBAyo Justa (1999), La imprenta en Madrid (1626-1650): materiales para su estudio e inventario, 2 vols, Madrid: Arco/Libros.

PASTORE Stefania (2010), Una herejía española. Conversos, alumbrados e inquisición (1449-1559), Madrid: Marcial Pons Historia.

PeEters-Fontainas Jean (1933), Bibliographie des impressions espagnoles des Pays-Bas, Louvain: J. Peeters-Fontainas.

PÉREZ PASTOR Cristóbal (1887), La imprenta en Toledo: descripción bibliográfica de las obras impresas en la imperial ciudad desde 1483 hasta nuestros días, Madrid: Imprenta de M. Tello.

PÉREZ PASTOR Cristóbal (1891-1907), Bibliografía madrileña, 3 vols, Madrid: Tipografía de los Huérfanos.

PÉREZ PASTOR Cristóbal (1895), La imprenta en Medina del Campo, Madrid: Sucesores de Rivadeneyra. REED Helen H. \& DADSON Trevor J. (2015), La princesa de Éboli. Cautiva del rey. Vida de Ana de Mendoza y de la Cerda (1540-1592), Madrid: Centro de Estudios Europa Hispánica y Marcial Pons Historia. Rosales Luis (1974), «La estimación literaria del Conde de Salinas», Studia Hispánica in honorem R. Lapesa (vol. 2, 531-547), 3 vols, Madrid: Gredos.

RUIZ FidALGo Lorenzo (1994), La imprenta en Salamanca (1501-1600), 3 vols, Madrid: Arco/Libros. SAlVÁ y MALlEn Pedro (1872), Catálogo de la Biblioteca de Salvá, 2 vols, Valencia: Imprenta de Ferrer de Orga.

SÁNCHEZ Juan M. (1913-1914), Bibliografía aragonesa del siglo XVI, 2 vols, Madrid: Imprenta Clásica Española.

SIMÓN DíAZ José (1950-1994), Bibliografía de la literatura hispánica, 16 vols, Madrid: C.S.I.C.

WeRUAGA PRIETo Ángel (1993), Libros y lectura en Salamanca. Del Barroco a la Ilustración 1650-1725, Salamanca: Junta de Castilla y León.

\section{ANEXOS}

\section{Apéndice $^{12}$}

Inventario de los libros latinos, italianos, portugueses, castellanos, franceses y de las ciudades del orbe, estampados unos de colores y otros de tinta, que se hallaron en la guardarropa y en diferentes partes, que eran del marqués mi señor de Alenquer y ahora son del duque mi señor de Híjar, su hijo, y lo mandó hacer su excelencia a 25 de septiembre del año 1642.

\section{Libros latinos}

1. Yndex del catálogo de los libros prohibidos mandado hacer por el arçobispo de Toledo año de mil y trecientos y treinta.

A pesar del título, que no puede ser correcto, ha de tratarse de la siguiente obra: Index et Catalogus Librorum prohibiturum, mandato Illustriss. Ac Reverendiss. D. D. Gasparis a Quiroga. Cardinalis Archiepiscopi Toletani..., Madrid: Alonso Gómez, 1583 (Pérez Pastor, 1891-1907, n. ${ }^{\circ}$ 178). 
2. Un prontuario de fray Rafael Sarmiento sobre la doctrina de San Bernardo.

Rafael Sarmiento, Promptuarium Conceptuum ad formandas Conciones totius anni, tam de tempore, quan de sanctis [...] ex D. Bernardo, Doctore melifluo selectum, Madrid: Miguel Serrano de Vargas, 1604 (Pérez Pastor, 1891-1907, n. ${ }^{\circ} 892$ ).

3. Expedicion cristiana compuesta por el padre Mateo Rizio de la Compañía de Jesús. Mateo Ricci, De Christiana expeditione apud Sinas suscepta ab societate Iesu... libri V, Lugduni: Horatii Cardon, 1616 (Goldsmith, 1969-1973: 474). El mismo año de 1616 se tradujo al francés, y fue impreso en la misma ciudad y por el mismo impresor: Histoire de l'expedition chrestienne au royaume de la Chine entreprise par les peres de la Compagnie de Jesus, comprise en cinq livres..., Lyon: Horace Cardon, 1616.

4. Anales de Cornelio Tácito comentado por Justo Lipsio.

Justus Lipsius, Ad Annales C. Taciti liber commentarius, 2 partes, Lugduni: Apud A. Gryphium, 1585 (British Library, 1924: 267). Véase también: Publius Cornelius Tacitus, Historiarum et Annalium libri qui exstant, ed. Justus Lipsius, Antuerpiae: C. Plantinus, 1574 (British Library, 1965: 195).

5. Justo Lipsio de milicia Romana.

Justus Lipsius, De militia romana libri quinque, Antuerpiae: Apud Viduam [de C. Plantino] \& J. Moretus, 1596 (British Library, 1965: 119).

6. Explicacion del Salmo miserere mei compuesto por Sebastian Gomez de Figeroa. Sebastián Gómez de Figueredo, Explicatio Psalmi quinquagesimi Miserere mei Deus, Salamanca: Juan Fernández, 1598 (Ruiz Fidalgo, 1994, n. ${ }^{\circ}$ 1464), con ediciones posteriores y revisadas en Lyon, 1601 y 1603. Véase también Dadson, 1998: 396, n. ${ }^{\circ} 43$.

7. Un tomo en que se contienen tres libros de los aforismos de Galeno y de Ypocatres comentados por el dotor Ambrosio Nuño.

Ambrosio Nunes, Enarrationum priores tres libros aphorismorum Hippocratis cum paraphrasi in commentaris Galeni..., Coimbra: Diogo Gomez Louveyro, 1603 (Simón Díaz, 1950-94: XVI, n. ${ }^{\text {os }}$ 1188 y 1189 ).

8. Un libro de Justo Lipsio llamado dotrina civil.

Justus Lipsius, Politicorum siue ciuilis dotrinae libri sex, Lugduni Batauorum: Apud.

F. Raphelengium, 1589 (British Library, 1965: 119).

9. Un libro de plática de aduogados en que se tratan cosas convenientes al Reino de Portugal compuesto por Manuel Mendez de Castro. [fol. 14v]

Manuel Mendes de Castro, Practica Lusitana, aduocatis, iudicibus, vtroque foro quotidie versantibus, admodum vtilis, \& necessaria. In quinque libros diuisa. Cum dugentis et quadraginta nouissimis Senatus decisionibus. Et centum contra cautellis. Item \& nonnullis animaduertionibus ad bonum publicum iustitice concernentibus. Et alijs vtilissimis ordinationum declarationibus, Lisboa: Jorge Rodríguez, $1619^{13}$.

10. Un libro de don Antonio de Gebara declarando las profecías del profeta Abaquc. Antonio de Guevara, In Habacuc prophetae vaticinium commentaria et ecphrasis, Amberes, Bellerus, 1609. Véase también: D. Antonii de Guevara. Exegemata in Habacuc, Madrid: Viuda de Pedro Madrigal, 1595 (Pérez Pastor, 1891-1907, n. 477).

11. Un libro de la regla de los carmelitas descalzos mandado imprimir por el papa Gregorio decimotercio.

Regula et Constitutiones fratrum Carmelitarum primitiuae obseruantiae... auctoritate Apostolica 
Sanctissimi domini nostri Gregorii XIII, Alcalá de Henares: Hernán Ramírez, 1585 (Martín Abad, 1991, n. ${ }^{\circ}$ 966).

12. Otra explicación del Salmo miserere mei a más de otra escrita atrás. Véase arriba el número 6; será otra edición que la reseñada allí.

13. Geroglificos de Juan Pieres Valeriano.

Giovanni Pierio Valeriano, Jeroglifici, ouero commentari delle occulte significationi de gli Egittij, \& d'altre nationi, Venetia: Gio. Antonio e Giacomo de' Franceschi, 1602 (British Library, 1990: 929), con ediciones también en 1604 y 1625. Véase también Dadson, 1998: 408, n. ${ }^{\circ}$ 147.

14. Otro libro de aduogacias por don Conrado Bruno.

Se trata de Conradus Brunus [Konrad Braun], autor de numerosos libros contra la sedición, los herejes, etc. Es posible que «aduogacias» sea un error de audición ${ }^{14}$, y que el verdadero título sea: Adversus novam historiam ecclesiasticam quam Mathias Illyricus et ejus collegae Magdeburgici per centurias ediderunt... admonitio catholica. Authore Conrado Bruno celeberrimo jurisperito et Canonico Augustano, [Dilingae]: [Sebaldus Mayer], 1565 (British Library, 1962: 158).

15. Otro de las antigüedades de Lisboa escrito por Andres Luzio.

Lucio André de Resende, Antiquitatum Lusitaniae et de municipio Eborensi, Colonia: In officina Birckmannica, 1600 (British Library, 1962: 732).

16. Otro de Manuel Barbosa sobre las remisiones de los dotores.

Si el autor es descrito correctamente, ha de tratarse de una edición más temprana de la obra siguiente: Manuel Barbosa, Remisiones Doctorum de Officiis Publicis Jurisdictione, Lisboa: A. Craebreck, 1681. Según el inventario de Lorenzo Ramírez de Prado, hay una edición de 1618 (Entrambasaguas, 1943, I: 94). Cfr. también Agustín Barbosa, Remisiones Doctorum qui varia logica Concilii Tridentini incidenter tractarunt, Lisboa: Pedro Craesbeeck, 1618 (Goldsmith, 1974, n. ${ }^{\circ} 46$ ), con otra edición en Valladolid: Jerónimo Morillo, 1621 (Alcocer y Martínez, 1926, n. ${ }^{\circ}$ 658). Véase también Dadson, 1998: 408, n. ${ }^{\circ} 151$.

17. Otro libro del padre Juan David de la Compañía de Jesús intitulado (adputandum putabam).

Jan David, Amputandum putabam radix stirps et germen errorum, Antverpiae: Trognaesius, 1612. Se trata del padre Joannes David, jesuita, cuyas fechas son 1545 a 1613.

18. Un vocabulario de tres lenguas por el maestro Felipe Cortona.

Se refiere a Filippo Venuti da Cortona, autor de numerosos diccionarios de italiano y latín, y de italiano y francés, impresos durante los siglos XVI (segunda mitad) y XVII. Dado el contenido de esta biblioteca, es probable que fuera un diccionario de italiano, francés, y latín, pero no he podido identificar un diccionario de estas características entre las obras de Venuti da Cortona.

19. Otro de versos en alabanza de su majestad del rey Felipe Tercero compuesto por un padre de la Compañía.

Es posible que sea: Pablo Albiniano Rajas (S.I.), Lagrimas de Çaragoça en la muerte de Filipo rey II de Aragon deste apellido y exequias que con aparato real à su memoria celebrò / recogiolas el P. Paulo de Rajas, de la Compañia de Iesus. En Çaragoça: por Juan de Lanaja y Quartanet, 1621 (Jiménez Catalán, 1927, n. ${ }^{\circ}$ 207). El texto empieza: «Oratio in Obitu Philipii Tertii». Como dice Jiménez Catalán: «Contiene poesías de varios autores, pero todas son anónimas» ${ }^{15}$. 
20. Más de oficio pii et cristiane pacis vere amantis viri esurgente aut vigente aresi autor Joan ecels a lobiano.

Joannes Hessels, De officio pii, et christianae pacis vere amantis viri, exvrgente, avt vigente haeresi... avthore Ioanne Hessels a Lovanio, sacrae theologiae in academia Louaniensi professore region, Antverpiae: ex Officina Christophori Plantini, 1566 (British Library, 1965: 94).

21. Juan Buoberi dies aestiva sive de umbra pagenion.

Ioannis Wouweri [Johannes van Wouwer], Dies aestiva sive de umbra paegnion; In laudem umbrae declamatio et carmen, Hamburgo: Michael Hering, 1610.

22. Insertacio de fide haeret servanda Jacobo Daza consulibus. [fol. 15r]

Daniel Plancius \& Heribert Rosweyde, De Fide Haereticis Servanda ex decreto concilii Constantiensis dissertatio, in qua, quae de Husso historia est, excutitur, Antverpiae: Officina Plantiniana, Moretus, 1610. Jacobo Daza [Jacques Dassa] es junto con Gilles De Merre uno de los dos Burgomaestres de Amberes dedicatarios de la Epístola de Heribert Rosweyde: « Amplissimvs Consvlibvs Iacobo D’Aça Aegidio de Merre Senatvi Popvloqve Antverpiensi».

23. Comentarios de César de belo dalequo.

Se trata de Caius Julius Caesar, Commentariorum de bello Gallico, «dalequo» siendo probablemente un error de pronunciación y luego de audición entre el que leía los títulos y el que los apuntaba. La obra comentada fue muy popular durante el siglo XVI y hay muchas impresiones, especialmente en Italia y Francia.

24. Luciano cronosolon.

Luciano de Samosata, poeta griego (c. 125 A.D.-después de 180 A.D.), escribió varias obras (hay 70 que sobreviven atribuidas a él), entre ellas una titulada: Las palabras de Cronosolón, sacerdote y profeta de Cronos. Hay una edición hecha por Erasmo: Luciani Samosatensis, Saturnalia, Cronosolon... Des. Erasmo Roterodamo interprete ex posteriori recognitione, Basileae: Apud Io. Frobenium, 1517 (ejemplo de la Bayerisches StaatsBibliothek).

25. Juanis estobeyde sentencia ex tesauris grecorum.

Ioannis Stobaei, Setentiae ex thesauris Graecorum delectae, quarum autores circiter ducentos \& quinquaginta citat..., Zurich: Christopher Froschover, 1543 (Gonzalo Sánchez-Molero, 1998: 381-382, n. ${ }^{\circ}$ 517; López Poza, 1990: 74).

26. Comentario de Francisquo Santi Brocense.

Francisco Sánchez de las Brozas [el Brocense], De arte dicendi liber unus, Salamanca: Pedro Laso, 1573 (Ruiz Fidalgo, 1994, n. ${ }^{\circ}$ 857). Contiene sus comentarios sobre pasajes de la Eneida de Virgilio, de ahí el título que le ponen en el inventario.

27. Joanis Bautista Ynacius benetus de las vidas de los emperadores. Joannes Baptista Egnatius, De Caesaribus libri III, Venetiis: In Aedibus Aldi \& Andreae soceri, 1517 (British Library, 1958: 231); Caesarum vitae post Suetonium conscriptae, 2 vols, Lugduni: Apud S. Gryphium, 1551 (British Library, 1924: 149). Se trata de la conocida Vida de los doce Césares de Suetonio, con comentarios de Joannes Baptista Egnatius; en algunas ediciones los comentarios de Egnatius van con otros de Erasmo.

28. Senequa naturales questiones.

Lucius Annaeus Seneca, Naturalium quaestionum libri septem, París: Ex officina

M. Vascosani, 1540 (British Library, 1924: 398).

29. Oratio comentado por Francisquo Landino.

Hay ediciones de finales del siglo Xv de Horacio comentado por Cristoforo Landinus, pero 
no he encontrado una comentada por Francisco Landino (es decir, Francesco Landini, que, por otro lado, era músico). Es posible que sea un error por este título: Francisci Luisini utinensis in librum Q. Horatii Flacci de arte poetica commentarius, Venetiis: [apud Aldi filios], 1554 (British Library, 1958: 334).

30. Los morales de Plutarquo.

Plutarco, Ethica, seu moralia opuscula, París: M. Vascosanus, 1544 (British Library, 1924: 357).

31. Enrique Clariano de georgafia.

Henricus Loritus [Enrique Glareano], De geographia, Venetiis: da Sabio, 1549 (British Library, 1958: 393); otra edición de París: G. Cauellat, 1551 (British Library, 1924: 287).

32. Concordia Belgiqae panegiriqus parnasicas a godoquo de Buert en la ciudad de Antuerpia.

Jodocus de Weerdt, Concordiae Belgicae Panegyricus Parnassicus a Iodoco de VVeerdt, Amberes: Ex Officina Plantiniana-Jan Moretus, 1609 (Entrambasaguas, 1943, II: 46). Como presidente del Consejo de Portugal, Salinas tuvo un pequeño papel en las negociaciones que llevaron al tratado de paz entre España y las provincias rebeldes de los Países Bajos en 1609, el llamado Tratado o Tregua de los Doce Años. Esta obra obviamente celebra el tratado y el fin de cuarenta años de guerra.

33. Euclides elementorum.

Euclides, Elementorum libri XV, Lutetiae: G. Cauellat, 1557 (British Library, 1924: 157).

34. Coronicon frarrum ordinis predicatorum autor fray Antonio cenense.

El autor es Antonius Senensis: Chronicon fratrum ordinis praedicatorum, Parisiis: Apud Nicolaum Nivellium, 1585.

35. Comentario de rebus in India Jacobo Tebio Lusitani autorii.

Jacobus Tevius, Commentarium de rebus in India apud Dium gestis anno salutis nostrae 1546. Iacobo Teuio Lusitano auctore, Conimbricae: excudebant Ioannes Barrerius \& Ioannes Aluarus, 1548. También hay una edición en Roma: apud Aloysium Zannettum, 1601 (British Library, 1990: 904).

36. Triunfalis tumulus ynvitisimi Caroli quinti.

Álvaro Cadaval Valladares de Sotomayor, Triumphalis Tumulus: Inuictissimi Caroli Quinti Caesaris Augusti Romanorum Imperatoris, Hispaniarum Clarissimi Regis triumphalis condignusque tumulus, Lisboa: Antonio Gonçalves, 1568 (Anselmo, 1926: 195, n. ${ }^{\circ}$ 684).

37. Panegiriquo dedicado a Nuestra Señora autor Juan Antonio Zabarati. [fol. 15v] El autor es Giovanni Antonio Zavattari, de quien se registran dos obras: Panegyricus Comestabili Castellae, Mediolani gubernatori, Mediolani: Apud F. Pagganellum, 1595 (British Library, 1958: 742), y De fori Mediolanensis praxi, \& nonnullis deprauationibus ex eo tollendis dialogus, Venetiis: Apud Hieronymum Polum, 1584. Dados los intereses políticos de Salinas (y la primera palabra del título), la primera obra reseñada parece el candidato más obvio.

38. Aristóteles comentado por un padre de la Compañía de Jesús.

Cfr. Commentarii Collegii Conimbricensis e Societate Iesu: In Vniversam Dialecticam Aristotelis Stagiritae, Coloniae Agrippinae: Gualtherius, 1607; Commentarii Collegii Conimbricensis, $e$ Societate Iesu, in duos libros de generatione \& corruptione, Aristotelis Stagiritae. ... Cum genimo, et copiosissimo indice, Venetia: apud Andream Baba, 1616; Commentarii Collegii Conimbricensis, $e$ Societate Iesu, super quatuor libros De Coelo, \& Meteorologicos, necnon Parua Naturalia, Aristotelis 
Stagiritae. ... Antehac in Germania impressi, sed nunc tertia vice in Italia typis excusi, summa cum diligentia correcti, \& extirpatis erroribus publici iuris facti. Cum duplice indice, Venetia: apud Andream Baba, 1616.

39. Imagines imperatorum. Icones sive Imagenes Imperatorum, Jenae: Typis Tobiae Steinmanni, Impensis Henningi Grosii civis \& Bibliopolaelispensis, Anno 1597.

40. Fundamento arismetiqua et geometriqua cum eorundum usu Ludolfo aceulen. Ludolph van Ceulen, Fundamenta arithmetica et geometrica, cum eorundem usu, in varii problematis, geometricis, partim solo linearum, ductu, partim per numeros irrationales, \& tabulas sinuum, \& algebram solutis, Lugduni Batavorum [Leiden]: apud Iacobum Marcum, 1615.

41. Bartolomé Pitisque de trigenometria.

Bartolomaei Pitisci, Trigonometriae sive de dimensione triangulorum libri quinque item problematum variorum nempe geodaeticorum, altimetricorum, geographicorum, astronomicoum libri decem, Francofurti: typis Nicolai Hofmanni, sumptibus Ionae Rosae, 1612. Véase también su: Trigonometria item problemata varia, Augusta Vindel, 1608.

42. Cristóbal Clavii de Societate Jesu comentando in esferam Joanis de Sacro Bosquo. Christophorus Clavius, Christophori Clavii bambergensis ex Societate Jesu, In Sphaeram Joannis de Sacro Bosco. Commentarius. Nunc quinto ab ipso auctore hoc anno 1606. recognitus, \& plerisq. in locis locupletatus. Accessit Geometrica, atque Uberrima de crepusculis tractatio, Roma: sumptibus Jo. Pauli Gelii ad signum navis Apud Aloisium Zannettum, 1606.

43. Discripcion del Reino de Afriqua por Felipo Piquafetan.

Filippo Pigafetta, Regnum Congo, hoc est Vera descriptio regni Africani, quod tam ab incolis quam Lusitanis Congo appellatur, Francofurti: excudebat Wolffgangus Richter, 1598.

44. Discripcion de Ameriqua y la India occidental y de Afriqua y de la India oriental, Ameriqua y Europa, en 6 cuerpos divi[di]dos, de diferentes autores escritos.

Cfr. Historiarum Americae admirandae narraciones, a variis Authoribus compilate, ad 12 partes, sex tomis, cum variis Iconibus Indorum \& Regionum, Francfort, 1590 (Entrambasaguas, 1943, II: 164-165). La forma de la entrada (varios autores y en 6 tomos) sugiere que puede ser esta edición. También podría tratarse de la serie en varias partes de America escrita por Theodor de Bry e impresa en Fráncfort en la década de 1590 (British Library, 1962: 159-160). Sin embargo, la referencia a «de diferentes autores escritos» sugiere una colección muy diversa de historias del Nuevo Mundo y Europa. Cfr. por ejemplo: Girolamo Benzoni, Historia Indiae Occidentalis, tomis duobus comprehensa. Prio, res ab Hispanis in India Occidentali hactenus gestas..., Ginebra: Eustathius Vignon, 1586. Como ésta, hay muchas historias de América, las Indias Orientales y Occidentales impresas en el siglo XVI.

45. Prontuario de fray Rafael Sarmiento.

Véase arriba el número 2.

46. 7 cuerpos de las principales ciudades del mundo autor Jorgius Bruina Agripinis. Georgius Bruin Agrippinas [Georg Braun] y Franz Hohenberg, Ciuitates orbis terrarum, Colonia: 1572-1618, 6 tomos (British Library, 1962: 148). Véase también Dadson, 1998: 408, n. ${ }^{\circ} 146$, donde se habla de dos tomos.

47. Joanis Brabus Comiso de medici, medicina et anatomia in Coninbrisenci academia profesoris. [fol. 16r]

Joannes Bravus Chamissus, D. medici, Medicinae, et Anathomiae in Conimbricensis Academia 
professoris De medendis corporis malis per manualem operationem. Tomus primus. Ad illustrissimum... Alfonsum Furtado de Mendoça Conimbrecensis Academice rectorem, Conimbricæ: typis Emmanuelis de Araujo Regij Vniuersitatis Architypographi excussum, 1605.

\section{Libros italianos $y$ franceses ${ }^{16}$}

[48] 1. Las obras de Cornelio Tacito en franzes.

Cfr. Publius Cornelius Tacitus, Les cuvres de Tacitus... et l'histoire romaine de C. Vellejus Paterculus nouvellement traduite en françois para J. B[audoin], París, 1610; o Les œuvres de C. Corn. Tacitus... : de nouveau traduites en François \& illustrées d'annotations, Paris: Richer, 1628. El IV duque de Uceda tenía la siguiente obra en francés de Tácito: Les maximes politiques de Tacite... par Mons. de la Serre, París: D. Langlois, 1662 (Martín Velasco, 2009: 432, n. ${ }^{0}$ 935).

[49] 2. Las cartas de Ovidio comentado por Remigio en italiano.

Publius Ovidius Naso, Epistole, trad. de Remigio Fiorentino [Nannini], Vinegia: G. Giolito \& fratelli, 1555 (British Library, 1958: 480).

[50] 3. Los metamorfosios de Ovidio en italiano.

Hay, por supuesto, bastantes traducciones de los Metamorphoseos de Ovidio en italiano durante todo el siglo XVI.

[51] 4. El mundo nuevo fray Tomas Estiliano en 4 cantos en italiano.

Tommaso Stigliani, Il mondo nuouo... Diuiso in trentaquattro canti. Cogli argomenti dell'istesso autore, Roma: appresso Giacomo Mascardi, 1628 (British Library, 1990: 879).

[52] 5. Las memorias de mosén Martín du Belay en franzes.

Martín du Bellay, Les mémoires de mess. Martin Du Bellay seigneur de Langey contenand le discours deplusieurs choses avenuës au royaume de France, depuis l'an 1513 jusques au trespas du roy François premier, París: P. L'Huillier, 1572 (British Library, 1924: 141).

[53] 6. El Petrarqua con una brevísima declaración de su vida en italiano.

Cfr. Francesco Petrarca, Il Petrarca. Con un pieno uocabulario, et con uno utilissimo rimario di L. Parmegiano (La uita del Petrarca, descritta da A. Vellutello), 4 partes, Venetia: P. Pietrasanta, 1554 (British Library, 1958: 505).

[54] 7. Las vidas de los hombres ilustres escritas por Plutarquo en francés escrito. Plutarco, Les vies des hommes illustres, trad. de J. Amyot, París: M. de Vascosan, 1559, con ediciones posteriores parisinas (British Library, 1924: 359).

[55] 8. El Petrarqua nuevamente traducido a la verdadera lecion con un nuevo discurso sobre la calidad de su amor.

Ha de ser algo parecido a: Francesco Petrarca, Il Petrarca. Con la dichiaratione del vero giorno del suo innamoramento, Lyon: appresso Gulielmo Rouillio, 1564.

[56] 9. El secretario cortesano en franzes.

Jean Puget de la Serre, Le Secretaire de la Cour ou la manière d'escrire selon le Temps, augmentée des compliments de la langue françoise, París: Pierre Billaine, 1624.

[57] 10. Danteo con nueva y útil exposición impreso en Leon [Lyon] en italiano. Suponiendo que se trata de Dante Alighieri, cfr.: Le terze rime, Lyon: G. Rouillio, 1575 (British Library, 1924: 128). 
[58] 11. Las observaciones de cosas memorables y singulares alladas en diferentes provincias por Pierre Velon de Le Mans en franzes.

Pierre Belon, Les observations de plusieurs singularités trouvées en Grece \& autres pays, París: B. Prevost, pour G. Corrozet \& G. Cauellat, 1553 (British Library, 1924: 46).

[59] 12. Torquato Taso de la Gerusalem en italiano.

Torquato Tasso, La Gerusalemme liberata, Parma: E. Viotto, 1581, con muchas ediciones posteriores (British Library, 1958: 660-661).

[60] 13. Las obras de Dámaso Trianbier en italiano.

Sin identificar.

[61] 14. Los anales de Cornelio Tacito.

Los Anales de Cornelio Tácito fueron impresos en latín durante todo el siglo xvI, en

Francia e Italia.

[62] El Petrarcha comentado antiguo. [fol. 16v]

Hay ediciones de Il Petrarca comentado desde finales del siglo xV y durante todo el XVI.

[63] Las relaciones de Theodoro Merues en alemán en tres thomos.

Theodor Meurer, Theodori Meurers relationis historicae continuatio, oder warhafftige

Beschreibung aller fürnemen und gedenckwürdigen Historien, Impressum Franckfurt:

M. Latomus, 1600-1615.

[64] Un libro grande que llaman la esphera de Astardan. [fol. 17r]

Es probable que el título quiera decir: un tratado de cosmografía o un atlas impreso en Ámsterdam, de tamaño grande. «Astardan» es un obvio error de audición.

\section{Entraron en la Galería los libros siguientes octubre 71642}

[65] Architetura Política - un tomo grande de mano.

Al tratarse de un manuscrito, es difícil identificarlo, aunque cfr: Gilbert Chazerat, Arquitectura política, Parisiis: ex typographia P. Moreau, 1644. Es posible que Salinas tuviera esta obra en manuscrito antes de que fuera impresa.

[66] Otro de architectura de Ju. de Viniola.

Iacomé de Vignola, Regla de las cinco ordenes de Architectura de Iacome de Vignola. Agora de nueuo traduzido de Toscano en Romance por Patricio Caxesi Florentino, Madrid: En casa del autor, 1593 (Pérez Pastor, 1891-1907, n. ${ }^{\circ}$ 422).

[67] Un tomo de Marco Galaso de fortificación.

Seguramente: Alghisi Galasso, Delle fortificationi libri tre di M. Galasso Alghisi da Carpi

architetto dell'eccellentiss. signor duca di Ferrara. Libri tre, Venezia: Grazioso Percacino, 1570

(British Library, 1958: 19). Nótese también, del siglo XVI, un Trattato di fortificazione de un tal Galeazzo Alessi.

[68] Otro tomo de fortificación de Hernando de Varli.

Sin identificar.

[69] Otro tomo de fortificación de Alexandro de Grote.

Sin identificar.

[70] Otro libro de fortificación de don Diego González de Medina y Barba, natural de Burgos. 
Diego González de Medina y Barba, Examen de fortificacion, hecho por don Diego Goncalez de Medina Barba, natural de Burgos..., Madrid: Licenciado Várez de Castro, 1599 (Pérez Pastor, 1891-1907, n. ${ }^{\circ}$ 624).

[71] La gineta de España por Pedro Fernández de Andrada.

Pedro Fernández de Andrada, Libro de la gineta de España, Sevilla: Alonso de la Barrera, 1599 (British Library, 1989: 77; Escudero y Perosso, 1894, n. ${ }^{\circ} 825$ ).

[72] El uso de las doce divisiones geométricas de Miguel Cofras.

Michel Coignet: «El uso de las divisiones geometricas puestas en las dos reglas pantometras, por las quales, con aiuda de un conpas comun, se pueden con gran facilidad resolver los problemas mathematicos, invencion geometrica sacada por la maior parte de los ocultos y secretos misterios que ay en la arte de los numeros, que vulgarmente se llama el arte mayor o algebra. Platicado y conpuesto por Miguel Conieto (Michel Coignet), natural de la ciudad de Anveres y matematico del serenissimo señor archiduque Alberto». Espagnol 351 (cote). Saint-Germain français, ${ }^{\circ}{ }^{\circ} 1193$; Séguier (ancienne cote). $\mathrm{XVII}^{\mathrm{e}}$ siècle. Papier. 55 feuillets. $340 \times 240 \mathrm{~mm}$. Manuscrit en espagnol. Bibliothèque nationale de France. Département des Manuscrits. El manuscrito contiene solamente esta obra, por lo que podría haber pertenecido en algún momento al mismo Salinas, aunque nada, parece, indica esta pertenencia. Se puede consultar en: <http://archivesetmanuscrits.bnf.fr/>.

[73] Otro libro de cosmographia Frisón.

Pedro Apiano, Libro de la cosmographia... aumentado por Gemma Frisio, Amberes: Juan Bellero, 1575 (Peeters-Fontainas, 1933: 10).

[74] Discripcion militar del caballero Aurelio.

Aurelio Cicuta, Disciplina militare del Sig. Caualliere Aurelio Cicuta; diuisa in tre libri Nouamente ristampata..., Venetia: appresso Lodouico Auanzo, 1575 (British Library, 1958: 184; Martín Velasco, 2009: 343, n. ${ }^{\circ} 290$ ).

[75] Otro de Quinto Tiberio de peste adgno regem Sardinii. [fols. 17v-18r] Quinto Tiberio Angelerio, Epidemiologia sive Tractatus de Peste, ad regni Saradiniae Proregem, Madrid: Juan Flamenco, 1598 (Pérez Pastor, 1891-1907, n. ${ }^{\circ}$ 559).

\section{Libros portugueses}

[76] El tomo primero de fray domingo f[rancis]co de Santis.

Sin identificar.

[77] Genealogía de Carlos V, Philipo $2=3$.

Sin identificar.

[78] Repertorio de las ordenaciones nuevas de Portugal de Castro.

Manuel Mendes de Castro, Repertorio das ordenações do Reyno de Portugal nouamente recopiladas: com as remissões dos doutores do Reyno, que as declarão \& concordia das Leys de Partida de Castella / composto pello licenciado Manuel Mendez de Castro..., aduogado nos conselhos de Castella..., Lisboa: Jorge Rodríguez, 1608.

[79] Un libro de quentas de Portugal.

Se trata probablemente de un libro de cuentas de los estados portugueses del propio conde, es decir, del marquesado de Alenquer y del reguengo de Guimarães. Varios libros de cuentas de esos estados se conservan entre los papeles de Salinas en AHPZ: Casa Ducal de Híjar. 


\section{Libros de romance ri $^{17}$}

[80] 1. Los fueros de Aragón.

Cfr. Fueros y Observancias del Reyno de Aragon, Zaragoza: Pedro Cabarte, 1624 (Jiménez

Catalán, 1927, n. ${ }^{\circ}$ 227). Para una edición anterior: Fueros y actos de Corte del Reyno de Aragon, hechos en las Cortes por la Catholica y Real Magestad del rey Don Philipe Nuestro Señor celebradas en la ciudad de Taraçona, Zaragoza: Lorenzo de Robles, 1593 (Sánchez, 1913-1914, n. ${ }^{\circ}$ 755). Dado que Rodrigo Sarmiento era duque consorte de Híjar en 1624 y por tanto uno de los nobles más importantes del reino de Aragón, es probable que Salinas tuviera en su posesión la edición de los fueros de ese año.

[81] 2. El agonía del tránsito de la muerte con los avisos y consuelos que cerqua de ella son provechosos por el maestro Valerio Venegas.

El autor es Alejo Venegas, y la obra: Agonia del transito de la muerte con los auisos y consuelos que acerca della son prouechosos... Dirigida a la ilustre señora Doña Ana de la Cerda, Condesa de Melito \&c. Autor el Maestro Alexio Vanegas, Madrid: Alonso Gómez, 1571 (Pérez Pastor, 1891-1907, n. ${ }^{\circ}$ 730). La obra trata de la muerte ejemplar de don Diego de Mendoza, conde de Mélito, en 1536 y fue publicada por primera vez en Toledo en 1537 (Pérez Pastor, 1887, n. ${ }^{\circ}$ 174). Fue dedicada a su viuda doña Ana de la Cerda, quien era protectora y mecenas del erasmista Alejo Vanegas (o Venegas). Los condes de Mélito eran los bisabuelos maternos de Diego de Silva y Mendoza.

[82] 3. Las virtudes del príncipe cristiano contra lo que escriben los autores de este tiempo por el padre Pedro de Ribadeneira de la Compañía de Jesús.

Pedro de Ribadeneyra, Tratado de la religión y virtudes que deue tener el Principe Christiano para gobernar y conseruar sus estados, Contra lo que Nicolas Machiauelo y los Politicos deste tiempo enseñan, Madrid: Pedro Madrigal, 1595 (Pérez Pastor, 1891-1907, n. 497).

[83] 4. Vida y virtudes de la venerable Ana de San Bartolomé por el maestro Crisóstomo Enríquez, coronista de la orden de San Bernardo.

Fray Crisóstomo Enríquez, Historia de la vida, virtudes y milagros de la Venerable Madre Ana de San Bartolomé, Compañera inseparable de la sancta Madre Teresa de Iesus, Bruselas: Viuda de Huberto Antonio, 1632 (Peeters-Fontainas, 1933: 47, n. $\left.{ }^{\circ} 441\right)$. Si no hay una edición anterior, está claro que este libro perteneció a Rodrigo Sarmiento de Silva y Villandrando, duque de Híjar, y no a su padre el conde de Salinas.

[84] 5. Instrucion y dotrina de novicios con que se han de criar los religiosos impreso por mandado de su Santidad.

Cfr. Instrucción de cómo se han de criar los novicios de S. Pablo y S. José, Madrid: 1595 (Pérez Pastor, 1891-1907, n. ${ }^{\circ}$ 479)

[85] 6. Vida y acción del rey don Juan el Segundo por don Agustín Manuel de Vasconcelos. Agustín Manuel de Vasconcelos, Vida y acciones del rey don Iuan el Segundo, Decimotercio de Portugal, Madrid: María de Quiñones, 1639 (Moreno Garbayo, 1999, n. ${ }^{\circ}$ 1961). Otro libro que no podría haber pertenecido a Salinas.

[86] 7. Memorial de cosas notables por don Íñigo López de Mendoza, duque cuarto del Infantado.

Íñigo López de Mendoza, duque del Infantado, Memorial de cosas notables, Guadalajara: Pedro de Robles y Francisco de Cormellas, 1564 (Salvá y Mallen, 1872, n. ${ }^{\circ} 2769$; Catalina García, 1899, n. ${ }^{\circ}$ 633). 
[87] 8. Un memorial dado a su majestad en las Cortes por el reino de Castilla. Sin identificar, pero probablemente un documento escrito a mano.

[88] 9. Historia de Nápoles por Pandolfo Columnucio, de Pesaro juriconsulto, dirigido al ilustrísimo señor conde de Sanyarote.

Pandulfo Colenucio, Historia del reino de Napoles, Auctor..., Iurisconsulto de Pesaro, Traduzido de lengua Toscana por Juan Vázquez del Mármol, Sevilla: Fernando Díaz, 1584 (Escudero y Perosso, 1894, n. ${ }^{\circ}$ 734).

[89] 10. Introducion a los proverbios de Senequa por el doctor Pedro Díaz dirigido al muy alto y poderoso señor, la majestad del rey don Juan el Segundo. [fol. 35v]

Los Proverbios de Séneca, traducidos por Pedro Díaz de Toledo y publicados por primera vez en Zamora en 1482, contienen una introducción o dedicatoria al rey Juan II de Aragón (Beardsley, 1970, n. ${ }^{\circ} 1$ ).

[90] 11. Advertencias de milicia espiritual compuesto por Gregorio Fagardo. Sin identificar.

[91] 12. Valerio Máximo traducido en castellano.

Podía ser: Valerio Máximo, De las hystorias romanas y carthagine[n]ses y d'otras muchas naciones y reynos por orde[ $n]$ de vicios y virtudes adicionado y nueuamente corregido, Sevilla: Juan Varela de Salamanca, 1514 (Salvá y Mallen, 1872, n. ${ }^{\circ} 2797$; Escudero y Perosso, 1894, n. ${ }^{\circ}$ 177). También hubo edición de Zaragoza: Pablo Hurus, 1495 (Haebler, 1903-1917, n. ${ }^{\circ}$ 663). Otra posibilidad sería: Diego Rodríguez de Almela, Valerio de las historias escolásticas, Medina del Campo: Nicolás de Piemonte, 1511 (Pérez Pastor, 1895, n. ${ }^{\circ} 1$ ). Hay edición madrileña de Alonso Gómez y Pierres Cosin, 1568 (Pérez Pastor, 1891-1907, n. ${ }^{\circ} 18$ ).

[92] 13. Alegación en favor de la compañía de la India oriental, comercios ultramarinos por Duarte Gómez Solís, al excelentísimo señor don Gaspar de Guzmán, conde de Olivares. Duarte Gómez Solís, Alegación en favor de la Compañia de la India Oriental, y comercios ultramarinos, que de nuevo se instituyó en el Reino de Portugal, [Lisboa]: [s.i.] 1628. Curiosamente, Gomes Solís escribió unos Discursos sobre los comercios de las dos Indias en forma de cartas al duque de Lerma y al secretario Juan de Ciriza en [Madrid]: Pedro Taso, 1622 (Pérez Pastor, 1891-1907, n. ${ }^{\circ} 1840$; Goldsmith, 1974, n. ${ }^{\circ} 156$ ).

[93] 14. Definiciones de la Orden y Caballería de Alcántara.

Diffiniciones de la orde[ $n$ ] y cavalleria de Alcantara, Madrid: Alonso Gómez, 1569 (Pérez Pastor, 1891-1907, n. ${ }^{\circ} 21$ ); hay otra edición por el mismo impresor en 1576 (Pérez Pastor, 1891-1907, n. ${ }^{\circ} 104$ ), y luego otra en Madrid en 1609 por Luis Sánchez (Pérez Pastor, 1891-1907, n. ${ }^{\circ}$ 1027). Véase también Dadson, 1998: 408-409, n. ${ }^{\circ} 152$.

[94] 15. Suma de todas las coroniquas del mundo llamado en latín Suplementum Coronite. Suma de todas las Cronicas del mundo, llamado en latin Suplementum Cronicarum, Valencia: G. Costilla, 1510 (Salvá y Mallen, 1872, n. ${ }^{\circ} 2775$ ).

[95] 16. Proverbios de Senequa traducidos de latín en español. Lucius Anneus Seneca, Proverbios, trad. de Pedro Díaz de Toledo, Zamora, 1482 (Beardsley, 1970, n. ${ }^{\circ}$ 1). Hay ediciones posteriores de Amberes 1552 (Peeters-Fontainas, 1933: 41, n. ${ }^{\circ}$ 402) y Medina del Campo 1552 y 1555 (Pérez Pastor, 1895, n. os 93 y 124).

[96] 17. Un certamen en alabanza de Santa Isabel en la Ciudad de Coimbra consagra[do] al rey nuestro señor Felipe 4 el Grande.

Francisco de Britto de Meneses, Sanctissimae Reginae Elisabethae poeticum certamen / dedicat, 
\& consecrat Academia Conimbricensis; jussu... D. Francisci de Britto de Menezes, Conimbricae, typis \& expensis Didaci Gomez de Loureyro, 1626. Como me comunica Fernando Bouza: «El título es latino, pero el contenido sólo parcialmente».

[97] 18. La execucion de politiquas y breuedad de despachos por el dotor Álbarez Corea. Luis Álvarez Correa, Execucion de Politicas y Brevedad de Despachos, Madrid: Imprenta del Reino, 1629 (Moreno Garbayo, 1999, n. ${ }^{\circ}$ 499). El autor es portugués y el libro va dedicado a don Alonso Hurtado de Mendoza, arzobispo de Lisboa y gobernador de Portugal.

[98] 19. Constituciones sinodales del obispado de Pamplona ordenadas por don Bernardo Rojas, obispo de Pamplona.

Bernardo de Sandoval y Rojas, Constituciones sinodales del Obispado de Pamplona, hechas y ordenadas por don Bernardo de Rojas y Sandoval, obispo de Pamplona, Pamplona: Porralis, 1591.

[99] 20. Las obras de Ausias Marquo, caballero valenciano, traduzidas en castellano por don Baltasar Romani.

Ausías March, Las Obras, trad. de Baltasar de Romaní, Valencia, 1539 (Salvá y Mallen, 1872, n. $\left.{ }^{\circ} 766\right)$. Véase también Dadson, 1998: 400-401, n. ${ }^{\circ} 80$.

[100] 21. Sumario de los tratados para aumento de la Real acienda en el año de mil y seiscientos. [fol. 36r]

Sin identificar, pero probablemente un documento escrito a mano.

[101] 22. Las politiquas o dotrina de Justo Lipsio que sirben para el gobierno del Reyno o principado traducidos de latín en castellano por don Bernardino de Mendoza. Justo Lipsio, Los seis libros de las políticas o doctrina civil, trad. de Bernardino de Mendoza, Madrid: Juan Flamenco, 1604 (Pérez Pastor, 1891-1907, n. ${ }^{\circ} 873$ ).

[102] 23. La regla de los frayles menores.

Probablemente, Francisco Ortiz Lucio, Compendium declarationum... super Euangelicam Regulam Seraphici Patris nostri Francisci, Madrid: Francisco Sánchez, 1584 (Pérez Pastor, 1891-1907, n. $\left.{ }^{\circ} 210\right)$. Véase también Dadson, 1998: 405, n. ${ }^{\circ} 115$.

[103] Suma de todas las coronicas Suplementum historiarum. Véase arriba el número 94.

[104] Las efemeridas de Francisco Suárez de Argüelles. Francisco Suárez de Argüelles, Ephemerides generales de los mouimientos de los cielos por doze años... Dirigido a Don Diego de Silva, Conde de Salinas y Ribadeo, Duque de Francavila, Madrid: Juan de la Cuesta, 1608 (Pérez Pastor, 1891-1907, n. ${ }^{\circ}$ 1022). Véase también Dadson, 1998: 406, n. $^{\circ} 127$.

(AHN, Nobleza, Osuna, C. 3.910, D. 148, fols. 14r-18r y 35r-36r)

\section{NOTAS}

1. Hay una lista de bibliotecas de escritores en Dadson (1998: 66-67). Naturalmente, desde entonces se han publicado más bibliotecas, de todo tipo, y hace falta una actualización del inventario de inventarios, publicado por primera vez por Laspéras (1980) y puesto al día en Dadson (1998: 516-532, Apéndice 2: «Lista de inventarios de bibliotecas particulares»). Hay mucha información sobre inventarios y bibliotecas particulares en Díez Borque (2010) y Díez Borque \& Bustos Táuler (2012). 
2. Seguimos careciendo de una biografía de este noble tan polifacético, pero en su lugar se pueden consultar: Gaillard (1983) y Dadson (2011b).

3. Los Inventarios A, B y C se encuentran en Dadson (1998: 391-409), pero no con esa numeración. El Inventario A aquí es el B allí, y el B aquí es el A allí. El Inventario D está sin publicar, y se encuentra como apéndice de este trabajo. Aquí voy a emplear el orden que he apuntado arriba en el texto.

4. Entre sus contemporáneos Salinas fue tenido por gran latinista, como señala Pedro de Mudarra y Avellaneda en su Carta al Conde de Santisteban: «También el señor Don Fernando Pacheco, el Condestable de Castilla, los duques del Infantado y de Feria, los condes de Lemos y de Salinas [...] en la noticia de la lengua latina pueden competir con los antiguos Tulios y Quintilianos» (citado en Rosales, 1974: 546).

5. Archivo General de Simancas, Secretarías Provinciales, Portugal, Libro 1.552, fol. 78, carta que se publica en Dadson, La correspondencia política de un Virrey. Las cartas enviadas desde Lisboa (1617-1622) por Diego de Silva y Mendoza, marqués de Alenquer, obra en preparación. Hemos señalado las partes en castellano con letra cursiva.

6. Algunos moriscos hacían lo mismo, es decir, leían las obras de polemistas españoles contra el Islam para saber de qué trataba su supuesta religión, habiendo perdido todo contacto con ella.

7. Gaspar de Quiroga, cardenal arzobispo de Toledo e Inquisidor General, era amigo y partidario de la madre de Salinas, Ana de Mendoza y de la Cerda, princesa de Éboli, y ella le escribió pidiendo su ayuda cuando fue encarcelada (Reed y Dadson, 2015: 380-381 y 478). Teniendo un ejemplar del Índice de libros prohibidos, Salinas habría sabido que al menos dos de los libros del Inventario B (Villarrubia, c. 1617) -los Salmos de David (n. ${ }^{\circ}$ 98) y el poema La reina Esther (n. $\left.{ }^{\circ} 104\right)$ - eran muy sospechosos y podrían traerle grandes problemas, según la identidad del autor. Si el primero lo tenía en la excelente traducción de Juan Pérez de Pineda (publicada en Ginebra por Jean Crespin en 1557, y dedicada a María de Austria, hermana de Carlos V), leía el libro de un prófugo de la Inquisición, que había tenido la sensatez de huir a París cuando tuvo lugar el proceso de su maestro Juan Gil (el doctor Egidio) en 1550, y, por tanto, varios años antes de que el Santo Oficio se ensañara de verdad con los llamados 'herejes' de Sevilla, donde Pérez de Pineda había sido rector del Colegio de la Doctrina. De París pasó a Ginebra, desde donde enviaba libros prohibidos a sus amigos y colegas en Sevilla, además de imprimir los suyos (Pastore, 2010: 309-311; Kinder, 1976). En 1560 fue quemado en efigie en el segundo auto de fe sevillano de aquel año, junto con sus colegas Juan Gil y Constantino Ponce de la Fuente (cuyos cadáveres fueron desenterrados y quemados). En cuanto a La reina Esther, era un poema muy popular entre los conversos y había una versión de João Pinto Delgado, judío portugués, que, viviendo en España, abrazó la religión católica, pero que luego volvió a la ley de Moisés y huyó a Francia. Su Poema de la reyna Esther se publicó en Ruán en 1627, en la imprenta de David du Petit Val (Dadson, 1998: 402-403).

8. «Tú solo y tus hermanos muy nobles asistíais con frecuencia a estas escuelas de la Sociedad de Jesús tan pronto como las abrimos, con celo increíble» (Dedicatoria).

9. Salinas sufrió toda su vida de malaria (tercianas y cuartanas, en la lengua de la época), y estaba cojo, el resultado probablemente de un accidente de la infancia. Sobre su mala salud, véase Dadson (2016): Introducción, y poemas 5 y 13.

10. AHPZ, Casa Ducal de Híjar, 1.a-81-12, palabras del mismo duque Rodrigo. En el Inventario B (n. - 37) hay una obra de Luis Pacheco de Narváez sobre la destreza de la espada, más varias gramáticas y ortografías de la lengua castellana que también podían haber servido para la educación del joven Rodrigo.

11. Véase Reed \& Dadson (2015, caps. 5 y 6), para las relaciones algo complicadas entre la princesa de Éboli y Teresa de Ávila.

12. Quiero dar las gracias al profesor Fernando Bouza Álvarez por la inestimable ayuda que me prestó en identificar algunos de los títulos de este inventario. 
13. En aquellas entradas donde no aparece ninguna fuente bibliográfica, como aquí, la referencia remite al catálogo virtual de la Universidad de Karslruhe, Alemania: <www.ubka.unikarlsruhe.de/kvk_en.html>.

14. Como es sabido, muchos inventarios post-mortem se hacían de la siguiente manera: uno (tal vez un chico o aprendiz) leía los títulos (de la portada o el tejuelo) en voz alta y otro (normalmente un librero o un escribano), sentado a una mesa, los iba apuntando, tal y como le llegaban. Era muy fácil así que hubiese errores de audición - de captación de sonidos. Muchos títulos de este inventario dan buena cuenta de esto.

15. Debo esta sugerencia al Dr. Manuel Pedraza Gracia, de la Universidad de Zaragoza, a quien doy las gracias.

16. La numeración empieza desde el 1 y va hasta el 14; luego para. Seguimos enumerando los libros por orden, poniendo el número entre corchetes.

17. De nuevo, esta sección empieza la numeración desde el 1 y va hasta el 23. Los últimos dos títulos no llevan numeración.

\section{RESÚMENES}

Diego de Silva y Mendoza, conde de Salinas y Ribadeo, ocupó diferentes cargos políticos al servicio de tres monarcas -Felipe II, Felipe III y Felipe IV- a lo largo de un periodo de unos cuarenta años. Paralelamente a esta actividad política, fue uno de los poetas de corte más influyentes, una de las personalidades más fascinantes de la época moderna: político, poeta, terrateniente y cortesano. A lo largo de su vida, reunió una importante colección de libros, en diferentes palacios y en diferentes épocas: en Valladolid (1603), en Villarrubia (c. 1617), y en Buenavista, Madrid (1630). Desde hace muchos años, he descubierto y publicado varios inventarios de sus libros. En este artículo, estudio un nuevo inventario, de unos cien títulos, establecido algunos años después de su muerte ocurrida en 1630. Cotejado con los inventarios anteriores, este último proporciona una idea precisa de sus gustos en cuanto a lectura en diferentes momentos de su vida privada y pública. Se percibe particularmente la importancia de los Jesuitas en su educación en su desarrollo posterior, a través de numerosos títulos de escritores jesuitas, en particular, panfletos poíticos.

Diego de Silva y Mendoza, comte de Salinas et Ribadeo, occupa différentes charges politiques au service de trois monarques - Philippe II, Philippe III et Philippe IV - sur une période d'environ quarante ans. Parallèlement à cette activité politique, il fut l'un des poètes de cour les plus influents et par conséquent, l'une des personnalités les plus fascinantes de l'époque moderne : politicien, poète, propriétaire terrien et courtisan. Tout au long de sa vie, il réunit une importante collection de livres, dans différents palais et à différentes époques: à Valladolid (1603), à Villarrubia (c. 1617), et à Buenavista, Madrid (1630). Depuis de nombreuses années, j'ai découvert et publié plusieurs inventaires de ses livres. Dans cet article, j'étudie un nouvel inventaire, d'environ une centaine de titres, établi quelques années après son décès intervenu en 1630. Confronté aux inventaires antérieurs, ce dernier livre une idée précise de ses goûts en matière de lecture à différents moments de sa vie privée et publique. On perçoit tout particulièrement l'importance des Jésuites dans son éducation et dans son développement futur, à travers de nombreux titres d'écrivains jésuites, en particulier, des pamphlets politiques. 
Diego de Silva y Mendoza, Count of Salinas and Ribadeo, served three monarchs-Philip II, Philip III and Philip IV-in various political capacities over a period of some forty years. At the same time, he was one of the leading poets at court. As such, he is one of the most fascinating personalities of early modern Spain: politician, poet, landowner, and courtier. During his life he accumulated books, keeping collections in his different palaces and at different times: Valladolid (1603), Villarrubia (c. 1617), and Buenavista, Madrid (1630). Over many years I have discovered and published various inventories of his books. In this article I study a new inventory of c. 100 titles taken a few years after his death in 1630, which, together with the earlier inventories, gives us an excellent idea of his reading tastes and how these reflect the different moments in his private and public life. In particular, we see the importance of the Jesuits in his education and future development, with numerous key titles by Jesuit writers, especially political tracts.

\section{ÍNDICE}

Palabras claves: Diego de Silva y Mendoza, bibliotecas privadas, colecciones de libros, política, Jesuitas

Keywords: Diego de Silva y Mendoza, private libraries, book collecting, politics, Jesuits Mots-clés: Diego de Silva y Mendoza, bibliothèques privées, collection de livres, politique, Jésuites

\section{AUTOR}

\section{TREVOR J. DADSON}

Queen Mary University of London 